\title{
Incidência de Leifsonia xyli subsp. xyli em variedades de cana-de-açúcar a serem empregados para multiplicação no estado de São Paulo
}

\author{
Alfredo Seiiti Urashima, Evandro de Jesus Ganem Júnior, Lauricema Barbosa Lozada Marchetti, Paulo Roberto \\ Gagliardi
}

Departamento de Biotecnologia Vegetal, Centro de Ciências Agrárias, Universidade Federal de São Carlos, Via Anhanguera Km 174, CEP 13600000 Araras, S.P.

Autor para correspondência: Alfredo Seiiti Urashima (alfredo@cca.ufscar.br)

Data de chegada: 06/05/2008. Aceito para publicação em: 18/10/2010.

1590

\section{RESUMO}

Urashima, A.S., Ganem Júnior, E.J., Marchetti, L.B.L., Gagliardi, P.R. Incidência de Leifsonia xyli subsp. xyli em variedades de cana-de-açúcar a serem empregados para multiplicação no estado de São Paulo. Summa Phytopathologica, v.36, n.4, p.322-328, 2010.

O raquitismo-da-soqueira, causada por Leifsonia xyli subsp xyli (Lxx) é uma das principais doenças da cana-de-açúcar pelo dano que acarreta à produtividade e estar presente em todas as regiões produtoras do país. Outro fator que contribui para sua importância na cultura é a dificuldade da sua identificação no campo pelo sintomas produzidos. Aliado a isso, mudas contaminadas juntamente com instrumentos de corte são os principais meios de disseminação da doença. O Laboratório de Genética Molecular (LAGEM) da UFSCar é um dos laboratórios que realizam exames de sanidade quanto ao raquitismoda-soqueira. O objetivo de presente trabalho foi o de examinar a incidência de Lxx nas canas enviadas para análise de sanidade ao LAGEM e reportar os resultados dos exames realizados entre os anos de 2005 e 2007. Esses resultados evidenciaram que RB867515 foi a variedade mais enviada em cada um dos três anos. Vinte e quatro das 98 variedades analisadas mostraram-se positivas quanto a $\mathrm{Lxx}$, com porcentagem variando de 0,4 a $38,9 \%$.

Palavras-chave adicionais: raquitismo-da-soqueira, cana-de-açúcar, doença.

\section{ABSTRACT}

Urashima, A.S., Ganem Júnior, E.J., Marchetti, L., Gagliardi, P.R. Incidence of Leifsonia xyli subsp xyli in sugarcane crops fron São Paulo State. Summa Phytopathologica, v.36, n.4, p.322-328, 2010.

The ratoon stunting disease (RSD), caused by Leifsonia xyli subsp $x y l i(\operatorname{Lxx})$, is one of the most important sugarcane diseases because of damage it inflicts to yield and its presence in all growing regions of the country. Another fact that makes it important to sugarcane crop is the difficulty of its identification in the field based on external symptoms. Moreover, systemic contaminated stalks and cutting materials are the main source of disease dissemination. The
Laboratório de Genética Molecular (LAGEM) of UFSCar performs routine diagnostic test for RSD. The objective of the present work was to examine the incidence of Lxx from samples received by the LAGEM between 2005 and 2007. The results showed that RB867515 was the most analyzed variety in every year and that 24 out of 98 varieties showed positive infection for Lxx with percentage varying from 0.4 to $38.9 \%$.

Keywords: ratoon stunting disease, sugarcane, disease

A cana-de-açúcar é uma das culturas mais importantes da agricultura brasileira, atualmente ocupa a terceira posição em área plantada no país, ficando atrás apenas da soja e do milho (14). Segundo a Conab (3), a produção nacional para a safra 2009 foi de 612,21 milhões de toneladas, ocupando uma área total de 7.531 milhões de hectares, sendo São Paulo o estado com a maior concentração dessa cultura com 4,1 milhões de ha.

Esta produção poderia ser ainda maior se alguns dos problemas fitossanitários da cultura fossem adequadamente resolvidos. Dentre esses, se destaca o raquitismo das soqueiras (RSD), considerada uma das mais importantes doenças da cultura por ter acarretado perdas de mais de dois bilhões de dólares nos últimos 30 anos somente no estado de São Paulo (16), inexistência de variedades imunes (6), além de estar presente em todas as regiões produtoras do país, de Pernambuco até o Paraná (1). No Espírito Santo e Oeste Mineiro, acredita-se que a alta incidência de RSD tem contribuído negativamente para a produtividade da cana-de-açúcar na região (15).

O RSD foi descrito pela primeira vez na Austrália em 1944 e em 1989 já havia sido relatada em 61 países (16). No Brasil, foi observada pela primeira vez em 1956 nos estados do Rio de Janeiro e Pernambuco (1).

Essa doença não apresenta sintomas externos específicos. Normalmente, o que se observa são crescimento irregular, raquitismo, afilamento e encurtamento de colmos, sintomas de murcha em períodos curtos de seca e conseqüente baixa produtividade, que podem ser facilmente confundidos com outros problemas abióticos. Entretanto, esses sintomas são mais pronunciados nas socas, observando-se muitas falhas porque as soqueiras não brotam ou emitem poucos perfilhos e raquíticas, fazendo com que a renovação do canavial se dê com maior frequiência (17). 
A disseminação da doença para novas áreas ocorre exclusivamente pelo plantio de mudas infectadas pela bactéria, já que essa bactéria ataca somente cana-de-açúcar, não se conhece nenhum inseto vetor do patógeno nem evidências de transmissão por sementes (9). Portanto, na instalação de um talhão comercial, faz-se necessário a obtenção de mudas em viveiros, cujos toletes pra plantio foram tratados termicamente. O tratamento térmico não elimina totalmente as células bacterianas presente mas o potencial de inóculo fica bastante reduzido.

A dificuldade de se identificar a doença no campo fez com que ela se disseminasse rapidamente por todas as regiões produtoras do mundo. A partir de 1980, foi isolado o agente causal da doença, a bactéria Leifsonia xyli subsp xyli (Lxx) (7), uma bactéria pequena coriniforme, gram positiva, habitante do xilema. Essa bactéria é facilmente disseminada através dos instrumentos e outros implementos agrícolas utilizados na cultura, especialmente na colheita (4). Com a tendência de aumento de colheita mecanizada da cana-de-açúcar no Brasil, a disseminação da Lxx, que ocorre durante cada colheita tende a aumentar a incidência da doença ao longo do ciclo da cultura, fazendo com que a severidade do RSD aumente em função dos cortes (12).

Assim, como os períodos mais importantes de disseminação da bactéria ocorrem no plantio e na colheita, torna-se preocupante a recente expansão da cultura para outras regiões do país, sem quantidade suficiente de material propagativo de boa qualidade, pois existe a possibilidade de que toletes empregados para essa expansão possam ser provenientes de talhões comerciais, sem a devida qualidade e assim iniciar um canavial com mudas contaminadas e posterior disseminação durante a colheita.

O laboratório de genética molecular (LAGEM) da UFSCar em Araras, tem um serviço de diagnóstico de raquitismo que é oferecido ao setor sucroalcooleiro para orientação quanto a sanidade das canas a serem empregadas nos viveiros de mudas. Assim sendo, o presente estudo teve o objetivo de reportar esses resultados, examinando a sanidade das diferentes variedades de cana quanto a incidência do raquitismo-da-soqueira entre os anos de 2005 e 2007.

\section{MATERIAL E MÉTODOS}

\section{Material Vegetal}

Nas Figuras 1, 3 e 5 encontram-se a relação das variedades com o número de amostras por variedade analisadas para Lxx durante os anos de 2005, 2006 e 2007. Essas amostras foram compostas de variedades coletadas aleatoriamente e enviadas por diferentes unidades de produção de várias regiões do estado de S. Paulo, seguindo-se a método de coleta determinada pelo LAGEM (http:/ /pmgca.dbv.cca.ufscar.br).

\section{Amostragem}

De cada talhão ou amostra, 100 canas mais raquíticas foram retiradas, sem o uso de elementos de corte, apenas quebrando-se o colmo na base. Os toletes tinham idade mínima de nove meses e aqueles com perfuração de broca foram evitados. De cada colmo, a extração da seiva do xilema foi feita dos entrenós basais, com o auxílio de um compressor de ar portátil e a seiva foi acondicionada em um tubo de microcentrífuga de 1,5 $\mathrm{ml}$. Após a retirada, duas gotas de solução $0,5 \%$ de cloreto de alquil dimetil benzil amônio foram adicionadas para transporte para o laboratório.

\section{Detecção}

A detecção da bactéria das amostras enviadas para o laboratório foi feita pelo teste de "Dot Blot Immunoassay" (13), conforme Carneiro Jr. et al. (2).

\section{RESULTADOS}

O número total de amostras analisadas para a incidência de Lxx no ano de 2005 foi de 16616 (Figura 1). Esse número se constituiu de uma elevada gama de variedades fazendo com que somente as mais representativas fossem individualizadas para uma análise mais detalhada. Assim, as sete variedades mais representativas corresponderam a 51,6\% do total. Dessas, a variedade RB867515 foi a mais analisada, representando $12,1 \%$ do total seguidas pelas RB855453 (9,4\%), SP81-3250 (7,6\%), SP91-1049 (6,8\%), SP832847 (6,0\%), RB835054 (5,0\%) e SP80-3280 (4,7\%). As outras variedades, num total de 41, totalizaram 8038 .

Quanto à incidência de $\mathrm{Lxx}$, das 48 variedades analisadas, somente 14 apresentaram infecção pelo patógeno (Figura 2). A variedade com a incidência maior de raquitismo foi a SP84-2025 com $25 \%$ de incidência, seguida da RB83-5054, com taxa de contaminação de $12,2 \%$. Outras duas variedades, SP90-3414 e SP86-6155, que não constaram como das mais enviadas para analise, apresentaram infecção de 10,7 e 7,3\%, respectivamente. A variedade mais analisada (RB867515) apresentou nível de infecção de 5,5\%, semelhante à da SP80-3280. Outras variedades apresentaram níveis de infecção variando entre 3,8 a 0,4\%. As variedades SP80-1842 e RB845210, que não haviam merecido destaque individual entre as canas mais analisadas apresentaram incidência de 3,4 e 2,2\%, respectivamente (Figura 2).

No ano de 2006 foram analisadas 26.358 amostras, sendo que sete variedades representaram $61 \%$ do total (Figura 3). A variedade RB867515 representou 20,2\% e as outras seis variedades tiveram uma distribuição mais uniforme, com variação entre 9,5\% e 3,8\%. As variedades RB855156 (6,6\%) e RB72454 (5,3\%) que não constavam como as mais enviadas no ano anterior, tiveram destaque em 2006. Os restantes 39\% analisadas foram compostos de 49 variedades.

Com relação à sanidade dessas amostras, o nível de doença no ano de 2006 se mostrou maior que o do ano anterior (Figura 4). RB855113, RB872552 e SP80-1842 foram as que apresentaram os maiores níveis de infecção, atingindo valores de 38,9, 34,4 e 24,3\%, respectivamente. Em seguida, o nível de infecção apresentado por RB72454, SP80-3280, RB855536, SP81-3250 e SP80-1816, ficou acima de $12 \%$, enquanto para as demais variedades, abaixo de $8 \%$. RB867515, com maior número de amostras analisadas no ano, apresentou infecção de $7,7 \%$. Como durante o ano, o número de variedades analisadas foi de 56 , a porcentagem de variedades de cana-de-açúcar infectadas por Lxx em 2006 foi de $25 \%$.

O número total de amostras enviadas no ano de 2007 foi de 18.108 (Figura 5), sendo que as variedades com maior número de amostras não diferiram muito das recebidas nos anos anteriores, já que as sete variedades mais representativas ocuparam $70,8 \%$ do total. RB867515, que já havia sido a mais analisada nos anos anteriores, se destacou nitidamente das demais, representando $32,6 \%$ do total, quase atingindo o total da soma das outras seis variedades individualizadas e ultrapassando o total de todas as outras variedades. As outras seis variedades com maior número de amostras foram RB855453, SP83-2847, SP81-3250, RB855156, 


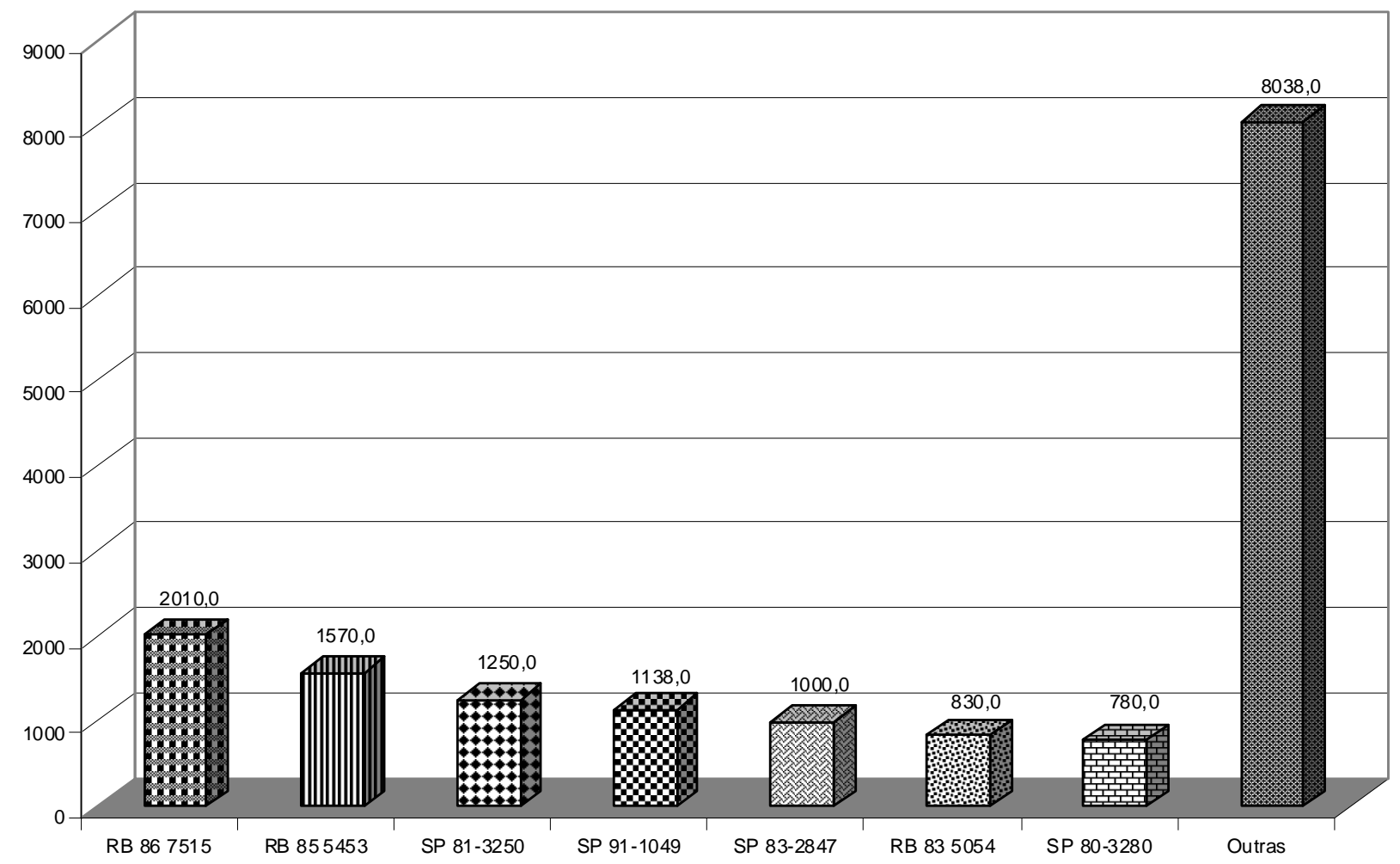

Figura 1. Número de amostras analisadas para Leifonia xyli subsp xyli por variedade de cana-de-açúcar no ano de 2005

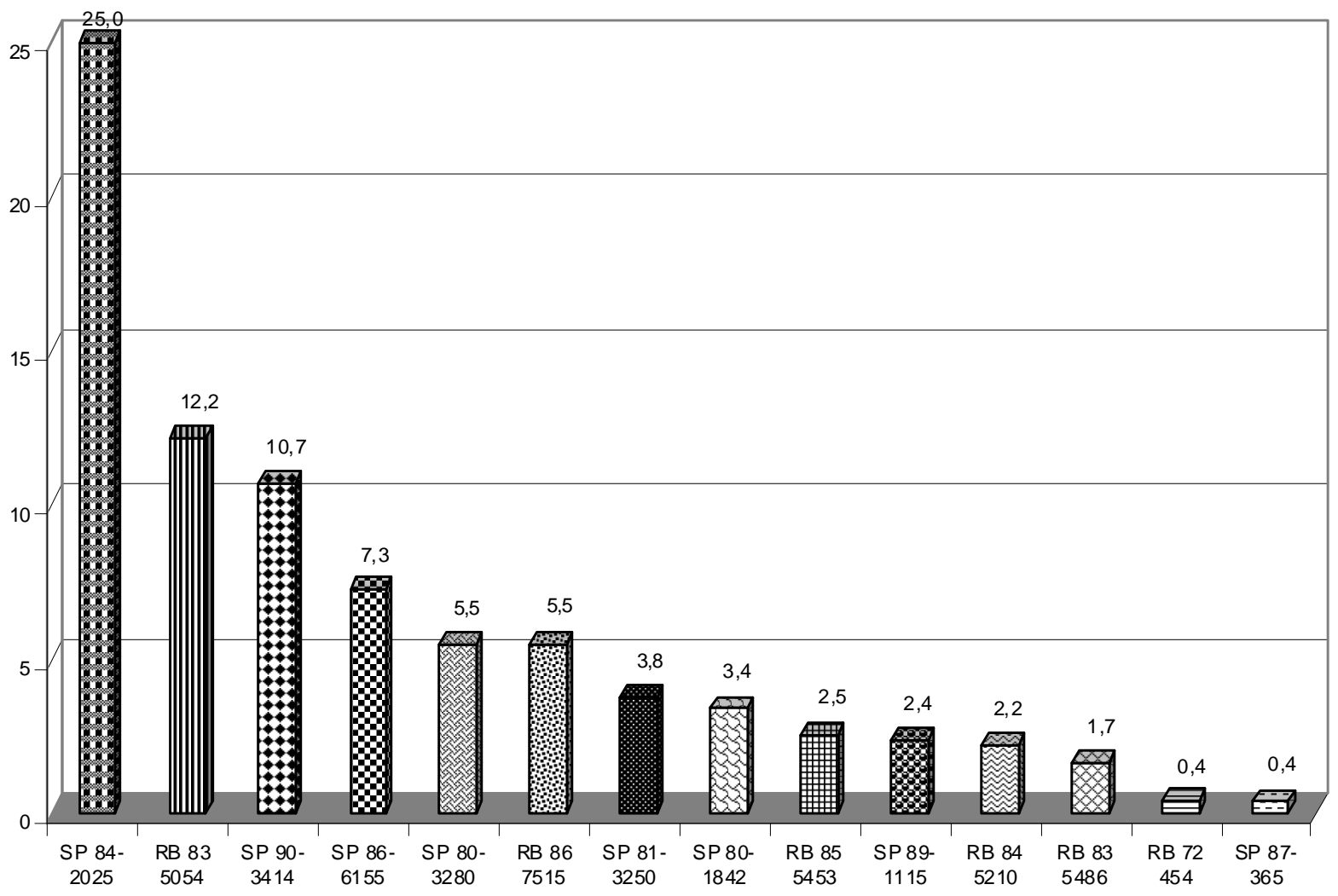

Figura 2. Porcentagem de infecção de Leifonia xyli subsp xyli em diferentes variedades de cana-de-açúcar no ano de 2005 


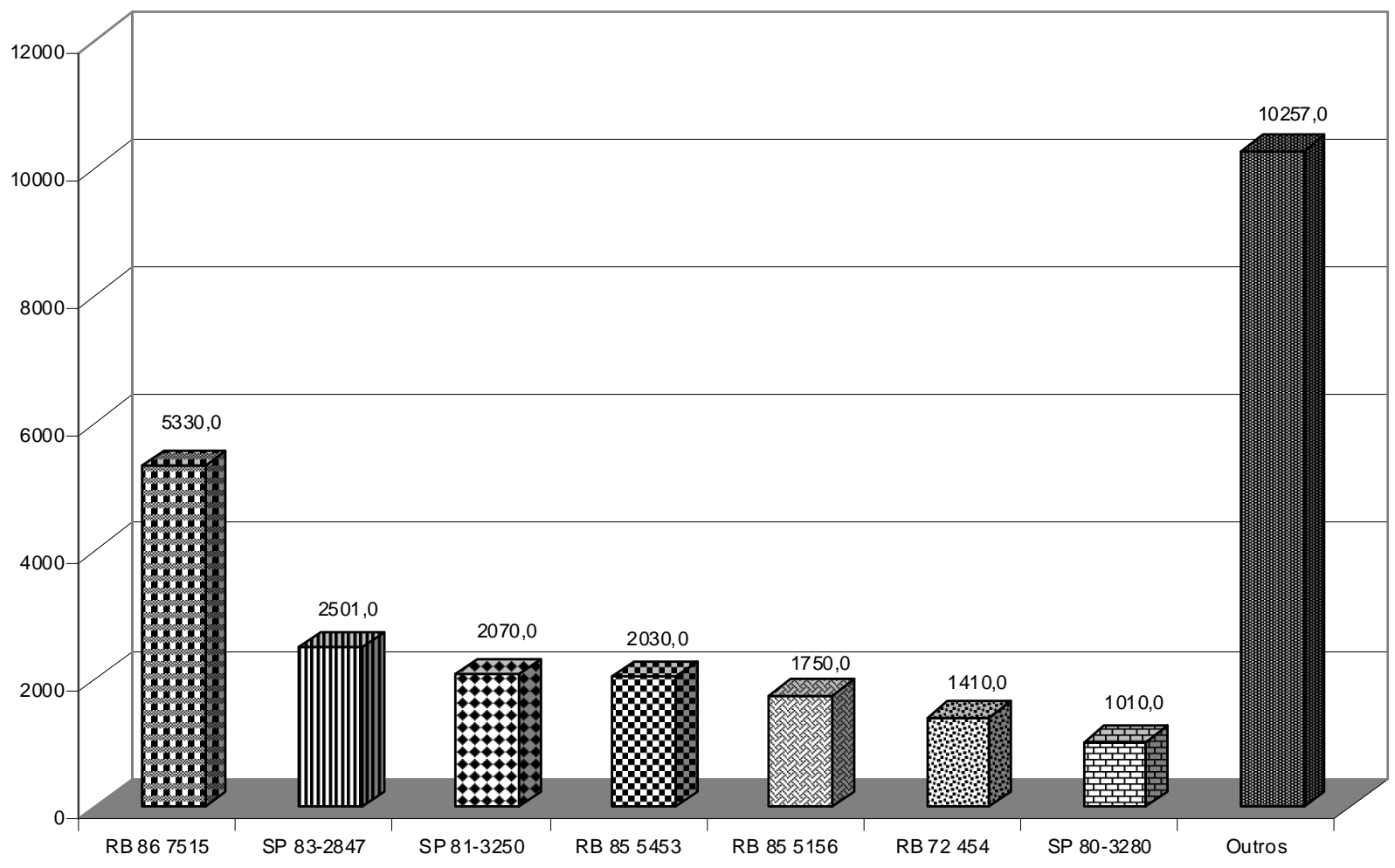

Figura 3. Número de amostras analisadas para Leifonia xyli subsp xyli por variedade de cana-de-açúcar no ano de 2006

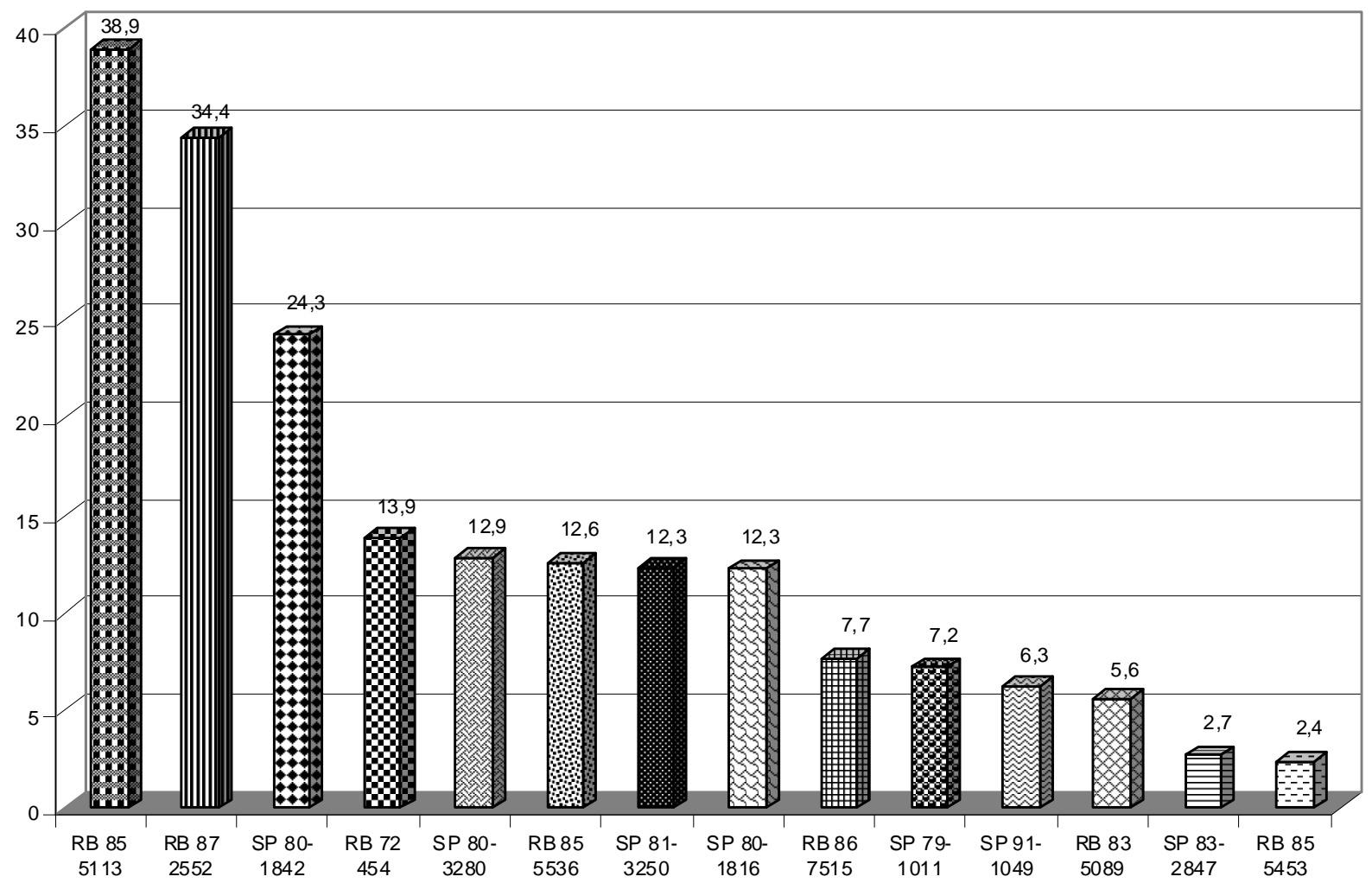

Figura 4. Porcentagem de infecção de Leifonia xyli subsp xyli em diferentes variedades de cana-de-açúcar no ano de 2006 
RB72454 e SP91-1049. Além dessas sete variedades, outras 35 variedades formaram $29,7 \%$ do restante.

Figura 6 mostra a porcentagem de infecção de Lxx dividida por variedades em 2007. Nesse ano, dez variedades mostraram-se positivas para o raquitismo. A variedade que mostrou maior infecção foi a SP801842, com 10,6\%, embora não estivesse incluída entre as sete que mais foram enviadas. A RB867515, apesar de ter sido a mais enviada também nesse ano, apresentou infecção inferior a $4 \%$. As variedades SP91-1049 e RB925345 foram as que apresentaram menor porcentagem de infecção $(0,4$ e $0,3 \%$, respectivamente).

\section{DISCUSSÃO}

Qualquer inferência mais generalizada sobre disseminação da Lxx e grau de suscetibilidade ao RSD das variedades de cana-de-açúcar em função dos dados do presente estudo deve ser feita com cuidado. Este estudo levou em conta somente o número de amostras enviadas para a análise pelas unidades produtoras dos materiais a serem empregados primordialmente para multiplicação nos viveiros de mudas e não de talhões com fins comerciais e foi feita de maneira aleatória. Exemplificando, variedades como SP84-2025 com infecção de 25\% (Figura 2), RB855113 com 38,9\%, RB872552 com 34,4\% e SP801842 com 24,3\% (Figura 4), foi obtida de um universo de 120, 180, 90 e 360 amostras, respectivamente. Esse pequeno número não permite assumir que essa alta incidência esteja prevalente nessas variedades em todo o estado de S. Paulo, pois existe a possibilidade que serem somente amostras pontuais. Outras variedades que tiveram um número de amostras mais representativa apresentaram incidência que permitem uma maior robustez nos dados. Variedades RB835054, que apresentou 12,2\% de infecção em 830 amostras analisadas (Figura 2) e SP80-3280 com 12,9\% em 1010 amostras (Figura 4), sugerem uma maior suscetibilidade dessas variedades a Lxx pois essas amostras foram provenientes de diversas localidades com diferentes condições edafoclimáticas, demonstrando que apesar das várias condições de tratos e cultivos essas variedades foram infectadas pela bactéria. Portanto, o presente trabalho, serve como indicativo da porcentagem da ocorrência de RSD nas variedades plantadas dentro do estado de S. Paulo.

Os resultados desse levantamento também mostraram que a incidência da doença não foi generalizada, mesmo com a coleta dirigida para amostras suspeitas, conforme sugestão de coleta do LAGEM. Das 98 variedades analisadas, somente 24 foram positivas à infecção de Lxx, o que corresponde a $24,5 \%$ do total enviado para a análise em laboratório.

Apesar disso, um ponto a se ressaltar é que as variedades enviadas em maior número de amostras e, portanto, podendo ser mais procuradas para plantio apresentaram infecção pela bactéria. Cinco das sete variedades mais analisadas em 2005; quatro das sete em 2006 e seis das sete em 2007 apresentaram-se positivas para o RSD (Figuras 2, 4 e 6). Dessas, a RB867515 que foi a mais popular em todos os anos, apresentou infecção em graus variados, mas não ultrapassando $7,7 \%$ (Figuras 2, 4 e 6). Os resultados obtidos mostraram que houve um aumento considerável das amostras dessa variedade de 2005 para 2007 , indicando claramente a preferência das unidades produtoras para seu emprego nas áreas de expansão da cultura na região oeste do estado de S. Paulo, onde ela mostra boa adaptação.

Assim, o fato dessa variedade ter mostrado infecção é preocupante porque a doença pode estar sendo levada pra regiões indenes, reforçando a importância de seu controle, seja por cultura de tecido ou tratamento térmico.

A cultura de tecido é pouco empregada pelas unidades produtoras devido ao alto custo para a montagem do laboratório. Além disso, apresenta outros inconvenientes como: variabilidade do material obtido

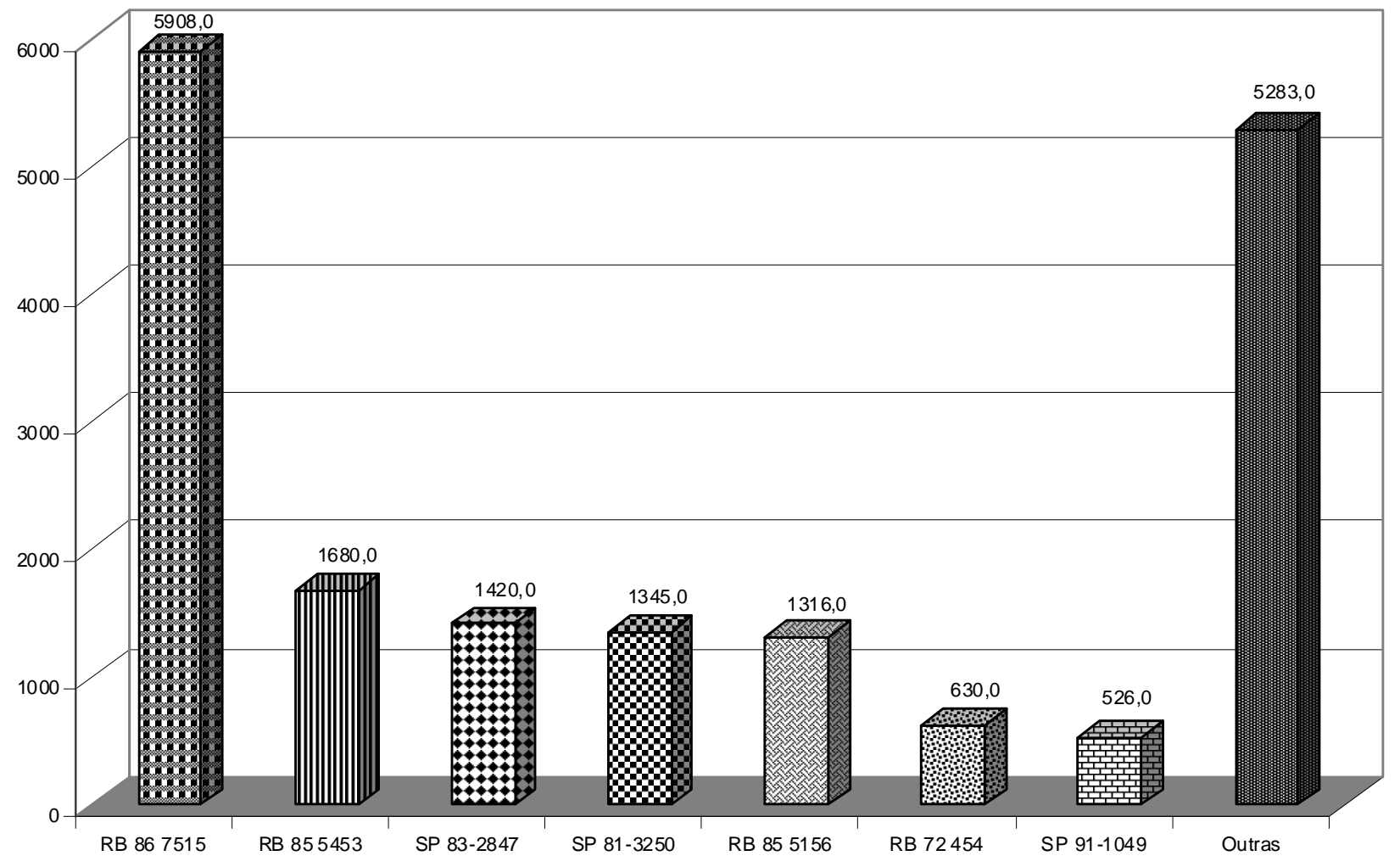

Figura 5. Número de amostras analisadas para Leifonia xyli subsp xyli por variedade de cana-de-açúcar no ano de 2007 


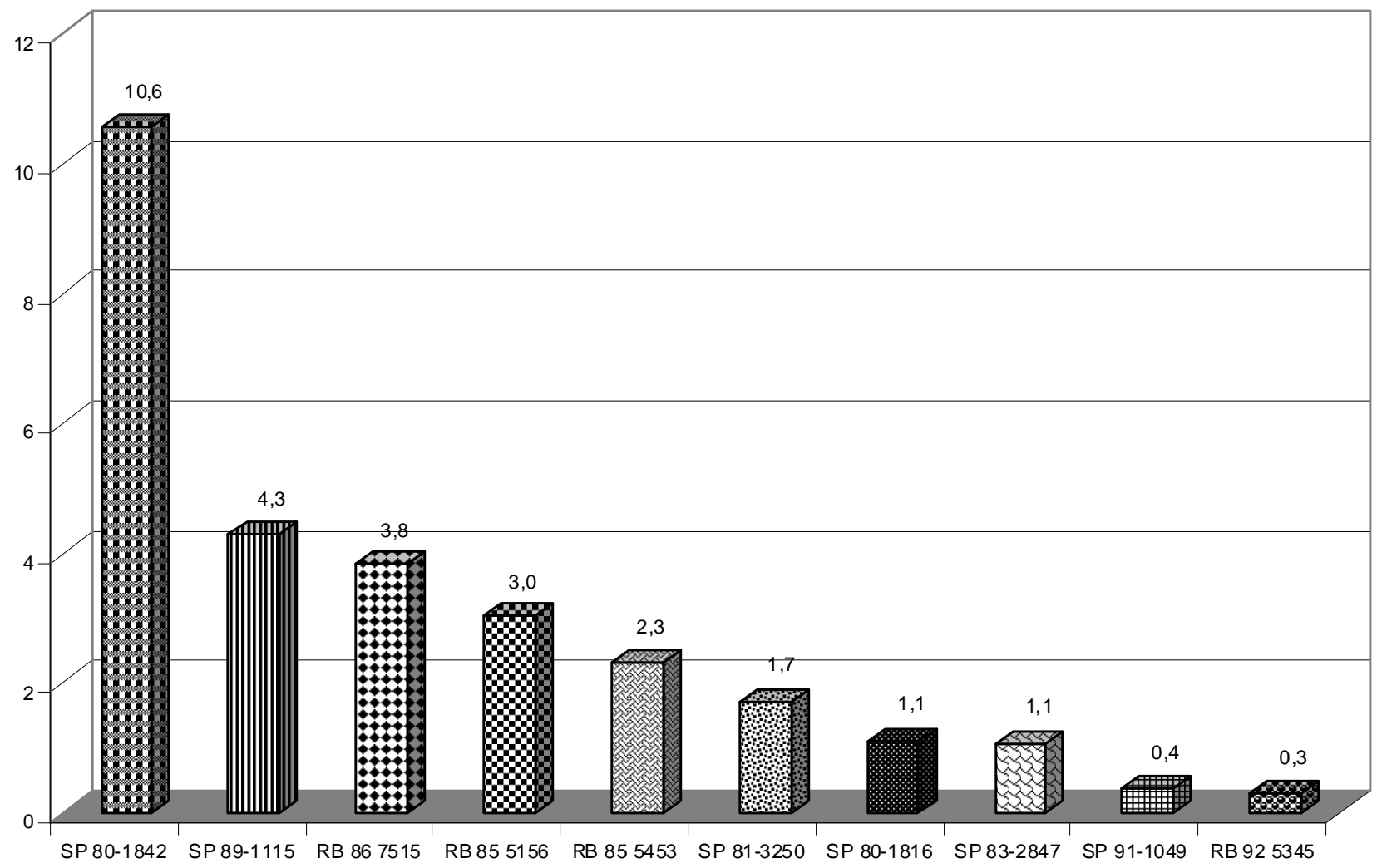

Figura 6. Porcentagem de infecção de Leifonia xyli subsp xyli em diferentes variedades de cana-de-açúcar no ano de 2007

devido ao emprego de produtos para a indução de calos, fazendo com que as características genéticas do material plantado no campo não sejam as mesmas da variedade de origem (11); diminuição nos componentes de produtividade: peso e diâmetro do tolete (11); possibilidade de escape no controle do patógeno (10).

A termoterapia emprega fundamentalmente duas combinações: $50^{\circ}$ $\mathrm{C}$ por $2 \mathrm{~h}$ (16) ou $52^{\circ} \mathrm{C}$ por $30 \mathrm{~min}$ (5). Embora a escolha da combinação a ser empregada esteja a critério da unidade produtora, a combinação $52^{\circ} \mathrm{C}$ por 30 min não apresentou efeito deletério na germinação, mas escape no controle da bactéria ao passo que $50,5^{\circ} \mathrm{C}$ por $2 \mathrm{~h}$ controlou o patógeno mas com efeito nocivo na germinação (8).

É louvável que as unidades produtoras tenham consciência da importância de se realizar o exame laboratorial para se saber sobre a sanidade das mudas ou qual a porcentagem de infecção de Lxx, para se melhorar a sanidade do talhão das grades lavouras pois a diagnose baseada somente em aspectos fenológicos não é segura devido a ausência de sintomas externos característicos (16). Espera-se que os resultados de infecção solicitados pelas unidades produtoras sejam utilizados como parâmetros para o plantio de mudas sadias, que é a medida mais eficiente de controle do agente do RSD.

\section{REFERÊNCIAS BIBLIOGRÁFICAS}

1. Almeida, I.M.G. Doenças causadas por bactérias. In: DinardoMiranda, L.L.; Vasconcelos, A.C.M.; Landell, M.G.A. (Ed.) Canade-açúcar. Campinas: Instituto Agronômico, 2008. cap.20, p. 437-450.

2. Carneiro Júnior, J.B.; Silveira, S.F.; Souza Filho, G.A.; Olivares, F.L.; Giglioti, E.A. Especificidade de anti-soro policlonal à Leifsonia xyli subsp. xyli. Fitopatologia Brasileira, Brasília, v.29, p.614-619, 2004.

3. Companhia Nacional de Abastecimento. Acompanhamento da safra brasileira: cana-de-açúcar: safra 2009/2010: terceiro levantamento (Dezembro/2009). Brasília, 2009. Disponível em: <http:/ / ww w.conab.gov.br/conabweb/download/safra/ 3cana_de_acucar.pdf.>. Acesso em 12 fev. 2010.

4. Comstock, J.C.; Shine Junior, J.M.; Davis, M.J.; Dean, J.L. Relationship between resistence to Clavibacter xyli subsp. xyli colonization in sugarcane and spread of ratoon stunting disease in the field. Plant Disease, St. Paul, v. 80, p.704-708, 1996.

5. Copersucar. Binômio tempo $\mathbf{x}$ temperatura no controle do raquitismo da soqueira (RSD) da cana-de-açúcar, pelo processo de termoterapia em gemas isoladas. São Paulo, 1989. 5p. (Cadernos COPERSUCAR, Série Melhoramento, 25).

6. Davis, M.J.; Dean, J.L.; Harrison, N.A. Quantitative variability of Clavibacter xyli subsp. xyli populations in sugarcane cultivars differing in resistance to ratoon stunting disease. Phytopathology, St. Paul, v. 78, p. 462-468, 1988.

7. Davis, M.J.; Gillaspie Junior, A.G.; Harris, R.W.; Lawson, R.H. Ratoon stunting disease of sugarcane: isolation of the causal bacterium. Science, New York, v. 210, p.1365-1367, 1980.

8. Ganem Júnior, E.J.; Fernandes Júnior, A.R.; Oliveira, C.R.; Urashima, A.S. Avaliação de diferentes tipos de tratamento térmico no controle do raquitismo-da-soqueira em cana-de-açùcar. Summa Phytopathologica, Botucatu, v. 34, p. 67, 2008.

9. Grisham, M.P. Ratoon stunting disease. In: Rao, G.P.; Saumtally, A.S.; Rott, P. (Ed) Sugarcane Pathology: bacterial and nematodes diseases. Enfield, USA: Science Publishers. 2004. v. 3, p. 77-96.

10. Hendre, R.R.; Iyor, R.S.; Kotwalm, M.; Kluspe, S.S.; Mascarenhas, A.F. Rapid multiplication of sugar cane by tissue culture. Sugar Cane, v.1, p. 5-8, 1983.

11. Hoy, J.W.; Bischoff, K.P.; Milligan, S.B.; Gravois, K.A. Effect of tissue culture explant source on sugarcane yield components. Euphytica, Wageningen, v. 129, p. 237-240, 2003. 
12. Hoy, J.W.; Grisham, M.P.; Danmann, K.E. Spread and increase of ratoon stunting disease of sugarcane and comparison of disease detection methods. Plant Disease, St. Paul, v. 83, p. 1170$1175,1999$.

13. Hsu, H.T. Development of enzyme linked, tissue blot and dot blot immunoassays for plant virus detection. In: Burns R (Ed.) Plant pathology: Techniques and protocols. New York, USA. Humana Press, 2009. cap.2, p. 15-25.

14. IBGE. Levantamento sistemático da produção agrícola. Disponível em <http://www.ibge.com.br> Acesso em: 12 fev. 2010.

15. Ponte, E.C.; Carneiro Júnior, J.B.; Silveira, S.F. Levantamento da incidência do raquitismo da soqueira da cana-de-açúcar em áreas de multiplicação do estado de Espírito Santo e oeste mineiro. Fitopatologia Brasileira, Brasília, v. 29, p. S190, 2004.

16. Tokeshi, H.; Rago, A. Doenças da cana-de-açúcar. In: Kimati, H.; Amorim, L.; Rezende, J.A.M.; Bergamin Filho, A.; Camargo, L.E.A. (Ed) Manual de fitopatologia: doenças das plantas cultivadas. 4. ed. São Paulo: Agronômica Ceres. 2005. v. 2, cap.21, p.185 - 196 .

17. Young, A.; Brumbley, S. Ratoon stunting disease of sugarcane: history, management and current research. In: Rao, G.P.; Saumtally, A.S.; Rott, P. (Ed) Sugarcane Pathology: bacterial and nematodes diseases. Enfield, USA: Science Publishers. 2004. v. 3, p. 97-124. 